\title{
Assessment of the ecological status of coastal areas and estuaries in France, using multiple fish-based indicators: a comparative analysis on the Vilaine estuary
}

\author{
Anik Brind' Amour ${ }^{1, a}$ and Jérémy Lobry \\ 1 IFREMER, Centre de Nantes, rue de l'île d'Yeu, BP 21105, 44311 Nantes Cedex 03, France \\ 2 CEMAGREF, Groupement de Bordeaux, 50 avenue de Verdun, 33612 Cestas Gazinet Cedex, France
}

Received 20 January 2009; Accepted 28 October 2009

\begin{abstract}
When reviewing the various fish-based community indicators aiming at assessing the ecological status of marine communities and/or ecosystems, a typology consisting of three major components emerges. The first component highlights the choice of relevant metrics associated with a level of organization (e.g. population or community). The second relies on the method used to combine the metrics (an aggregated indicator or a synoptic table). The third refers to the type of analysis (direct or indirect) that is used to establish the link between the metrics and a given pressure. In this paper we use the Vilaine coastal-estuarine fish communities as a case study to discuss and relate two different approaches to the suggested typology. The first approach (time-trend approach) is based on historical series of data, whereas the second approach (multi-metric index, MMI) is based on a geographic series including various French estuaries. They were developed or adapted from French studies but are representative of the approaches used in Europe. When applied to the case study, they differed in their diagnosis: the time-trend approach indicated that the bay of Vilaine habitat was deteriorating, whereas the MMI, which compares many French estuaries, indicated a good environmental state. Differences and complementarities between the approaches are thoroughly discussed with respect to the three mains components of the typology. This work appears at a particular moment, when several fish-based indicators are being developed in France and the rest of Europe. It intends to serve as an element of the ongoing reflection concerning the limitations of the various approaches that can be used to develop such indicators.
\end{abstract}

Key words: Coastal ecosystems / Fish communities / Indicators / Integrated approaches / Metric / Typology of fish indicators

Résumé - En passant en revue les différents indicateurs de communautés de poissons qui évaluent l'état écologique des communautés marines et/ou des écosystèmes marins, une typologie constituée de trois grandes composantes émerge. La première souligne le choix des métriques en association avec leur niveau d'organisation comme, par exemple la population ou la communauté. La seconde est basée sur la méthode utilisée pour combiner ces métriques (agrégative ou sous forme de tableau synoptique). La troisième se réfère au type d'analyse (directe ou indirecte) qui est utilisé pour mettre en relation les métriques avec une pression donnée. Le présent travail utilise la baie de Vilaine comme un cas d'étude afin de discuter et de relier deux différentes approches à la typologie proposée. La première approche (dite de la tendance temporelle) porte sur des séries de données historiques alors que la seconde approche (nommée indice multi-métrique, MMI) porte sur une série géographique, c'est-à-dire sur des données portant sur un ensemble de fleuves en France. Elles ont été développées et adaptées à partir d'approches françaises mais sont représentatives des approches plus largement utilisées en Europe. L'application de ces approches au cas d'étude conduit à des résultats différents. L'approche des tendances temporelles suggère que l'écosystème de la baie de Vilaine se dégrade, alors que l'approche MMI, qui est basé sur la comparaison de plusieurs estuaires, indique que cet écosystème est dans un bon état écologique. Les principales différences et similarités entre les approches sont largement discutées eu égard à la typologie proposée. Ce travail émerge à un moment où plusieurs indicateurs basés sur les communautés de poissons sont en développement en France et dans le reste de l'Europe. Il a donc pour but de contribuer à cette réflexion en proposant un regard sur les limites des différentes approches qui peuvent être utilisées pour construire ces indicateurs.

a Corresponding author: Anik.Brindamour@ifremer.fr 


\section{Introduction}

Recent integrated approaches to fisheries management (such as the ecosystem approach to fisheries, EAF) and policy instruments for environmental management (such as the European Water Framework Directive, EWFD) require the use of indicators to assess the environmental status of aquatic ecosystems. Efforts have been dedicated to the development of ecosystemic and fish-based indicators to assess changes in freshwater ecosystems (Karr 1981; Mercado-Silva et al. 2002; Roset et al. 2007) and in open-sea exploited fish communities (Rice 2003; Rochet and Trenkel 2003; Babcock et al. 2005; Clua et al. 2005; Shin et al. 2005; Methratta and Link 2006). It is only very recently that efforts have been directed towards the development of similar indicators in coastal-estuarine communities (Harrison and Whitfield 2004; Breine et al. 2007; Henriques et al. 2008). Compared to more offshore habitats, where fishing may be the main stressor, coastal-estuarine areas are probably the aquatic ecosystems where anthropogenic and natural pressures combined reach their highest levels (Hénocque and Denis 2001) and where similar biological responses to these pressures are most often observed (e.g. tolerant species to organic-rich systems).

It is well known that coastal-estuarine environments are among the most productive aquatic ecosystems (Costanza et al. 1997). However, despite its high productivity, the coastalestuarine realm displays relatively low biological diversity values when compared to other ecosystems such as freshwater or marine ecosystems (McLusky and Elliott 2007). This is notably striking in fish communities in which only a restricted number of species is well adapted to such stressful conditions. This atypical relationship between biodiversity and productivity in coastal-estuarine ecosystems was recently underlined by Elliott and Quintino (2007) and further identified as the Estuarine Quality Paradox, which suggests that, notwithstanding the relatively small number of species (low species richness), all the essential functions in these ecosystems might be provided (high functional diversity). It is indeed because of that paradox that different authors (Costanza and Mageau 1999; ISRS 2004) stressed the necessity of integrating structural (i.e. taxonomic) and functional attributes of fish communities when developing fish-based indicators in these ecosystems.

\section{Why use fish-based indicators?}

By responding physiologically to their environment, fish are likely to integrate the effect of single and cumulative changes across a wide range of environmental conditions and are considered as integrative indicators of the state of coastalestuarine ecosystems (Whitfield and Elliott 2002; Harrison and Whitfield 2004). As the lifestyle of fishes making up fish communities varies, inter alia, from sedentary to mobile and shortto long-lived, involving various feeding modes and trophic levels, they are sensitive to ecosystem conditions and may provide record of environmental stresses at multiple spatial and temporal scales. Implicitly, this means that monitoring the state of fish communities using fish-based indicators is a good way of approaching the environmental status of the ecosystem.

This work aims at suggesting and discussing a typology of existing approaches that use fish-based indicators to assess

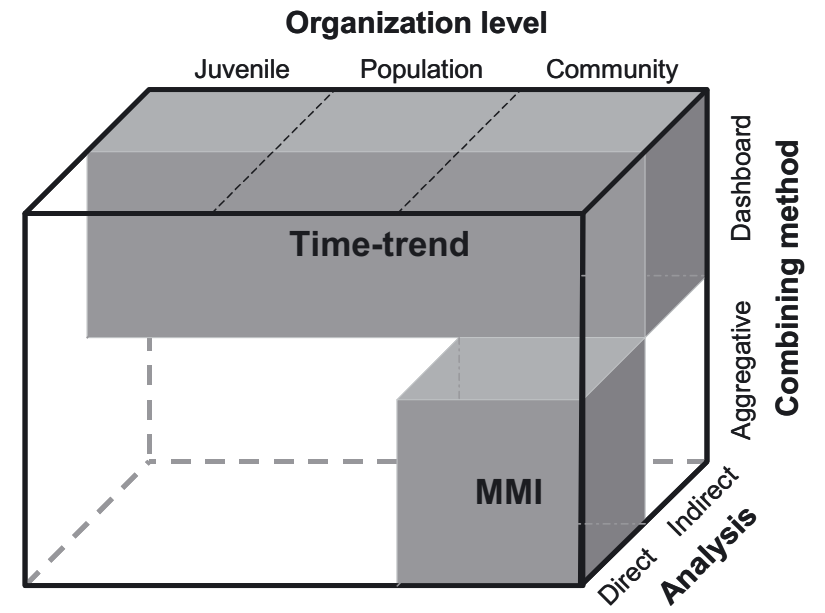

Fig. 1. Schematic 3D view of the different components defining the existing approaches that use fish-based indicators to assess the ecological status of coastal-estuarine ecosystems. The grey rectangles identify the two approaches, Time-trend and Multi-Metric Index (MMI), discussed in the present paper.

the ecological status of coastal-estuarine ecosystems. Using the Vilaine estuary as a case study, it also compares and critically reviews the use of two specific approaches in assessing the ecological status of that estuary. Unlike other recent studies which mainly review the performance of existing indicators or suggest new ones for assessing the quality or sustainability of estuarine ecosystems (Harrison and Whitfield 2004; Roset et al. 2007), the present work focuses more on the French approaches and is by no means an exhaustive review of existing fish indicators or methodologies in the estuarine-coastal environment. The terms "indicators" and "metrics", used throughout the text, have been given different meanings. In the present paper, a metric is "a measurable factor that represents some aspect of biological assemblage, structure, function, or other community component" (Coates et al. 2007). A metric becomes an indicator when it is (monotonously) related to a pressure (either natural or anthropogenic). A relevant indicator is a metric that, notwithstanding the environmental context, is able to robustly discriminate different levels of pressures in different ecosystems (or different time periods).

\section{Methods}

\subsection{A typology of fish-based indicators in coastal-estuarine ecosystems}

Three main components can be highlighted when reviewing the existing approaches that define the ecological status of coastal-estuarine ecosystems using fish-based indicators (Fig. 1). The first component refers to the level of biological organization (subpopulation, population and community) at which the relevant metrics can be elaborated when developing the indicators. The second component refers to the methods (aggregative computation or synoptic representation, or "dashboard") commonly used to combine the metrics. The third component describes the types of analyses (direct or indirect) 
Table 1. Hierarchical typology of metrics and types of analysis commonly used to develop fish indicators in coastal ecosystems.

\begin{tabular}{|c|c|c|c|}
\hline \multirow[t]{2}{*}{ Metric } & \multirow[t]{2}{*}{ Notation } & \multicolumn{2}{|c|}{ Type of Analysis } \\
\hline & & Indirect & Direct \\
\hline \multicolumn{4}{|l|}{ Juvenile-based indices } \\
\hline Average length for the first mode (G0) of population $i$ at time $t$ (year) & $L_{(\mathrm{G} 0) i, t}$ & $\mathrm{x}$ & \\
\hline ln-transformed abundance of juvenile (G0) species $i$ at time $t$ (year) & $\ln (N)_{(\mathrm{G} 0) i, t}$ & $\mathrm{x}$ & \\
\hline \multicolumn{4}{|l|}{ Population-based indices } \\
\hline ln-transformed population abundance for species $i$ at time $t$ (year) & $\ln (N)_{i, t}$ & $\mathrm{x}$ & \\
\hline Biomass for species $i$ at time $t$ (year) & $B_{i, t}$ & $\mathrm{x}$ & \\
\hline \multicolumn{4}{|l|}{ Community-based indices } \\
\hline \multicolumn{4}{|l|}{ Taxonomic (structural) indices } \\
\hline - Diversity indices (Pielou's evenness ${ }^{1}$ ) & $J=H / \ln (S)$ & $\mathrm{x}$ & \\
\hline - Taxonomic diversity and distinctness indices & $\Delta$ and $\Delta^{*}$ & $\mathrm{x}$ & \\
\hline \multicolumn{4}{|l|}{ Non-Taxonomic (functional) indices } \\
\hline - Total abundance in community at time $t$ (year) & $N_{t}$ & & \\
\hline - Total biomass in community at time $t$ (year) & $B_{t}$ & & \\
\hline - Total density in community & $D T$ & & $\mathrm{x}$ \\
\hline - Number of diadromous taxa & $C A$ & & $\mathrm{x}$ \\
\hline - Relative abundance of estuary-dependent taxa & $N_{\text {Dep }}$ & $\mathrm{x}$ & \\
\hline - Ratio of estuary-dependent ${ }^{2} /$ independent taxa & $R_{\text {Dep/Indep }}$ & $\mathrm{x}$ & \\
\hline - Density of marine juveniles in community & $M J$ & & $\mathrm{x}$ \\
\hline - Density of benthic fish in community & $B$ & & $\mathrm{x}$ \\
\hline \multicolumn{4}{|l|}{ Discrete measures } \\
\hline - Diversity of functional guilds ${ }^{3}$ (Simpson index) & $F G_{\text {Simp }}$ & $\mathrm{x}$ & \\
\hline Bay of Vilaine approaches & & Time-trend & MMI \\
\hline
\end{tabular}

${ }^{1}$ Pielou's evenness $(J)$, Shannon index $(H)$, and species richness $(S)$

${ }^{2}$ Dependent taxa $=$ resident + estuarine-dependent taxa

${ }^{3} F G$ are the functional guilds proposed by Elliott and Dewailly (1995) which characterize a typical European estuary.

used to validate the relation between the metrics and the environmental or anthropogenic stresses. The combination of these three components characterizes the main approaches used in Europe. In the present study, the term "coastal-estuarine" corresponds to two different parts of the estuarine ecosystem: (i) the nearshore outer part of the estuary, where bathymetry can rise up to $40 \mathrm{~m}$ and salinities up to $35 \mathrm{mg} \mathrm{L}^{-1}$, and (ii) the estuary sensu stricto, integrating marine to freshwater conditions.

\subsubsection{Component 1: choosing the candidate metrics from different biological organization levels}

In this paper, as well as in many other studies, fish-based metrics for coastal ecosystems are classified in hierarchical groups, ranging from those estimated at the level of a subpopulation (e.g. juveniles of a population) to those measured at the community level (Fig. 1, Table 1). This classification is supported by the fact that biological organization is hierarchically structured and that increasing levels of organization often lead to decreasing mechanistic understanding (i.e. loss of causality) and increasing ecological significance (i.e. gain in generalization) (Adam 2002). Concurrently, anthropogenic stress can be regarded as a "quantifiable effect of human-induced activities reducing the fitness for survival at any of the organizational levels" (Whitfield and Elliott 2002).
Consequently, selecting candidate metrics within that hierarchy is likely to help addressing the many dimensions (i.e. responses) of an impacted ecosystem. Trophodynamic metrics computed from network analyses, such as connectivity or ascendancy (Baird and Ulanowicz 1993), are voluntarily omitted from the paper as we do not consider them as species-based metrics per se.

\section{Juvenile-based metrics}

The first level of organization of the metrics relates to a fraction of the population under study (i.e. subpopulation level of organization). In the present study, the metrics at the subpopulation level relate to the juveniles. It relies on length-frequency distributions and identifies the first age group present in a given population and year. All measured individuals in that group are presumed to belong to a cohort or year-class, identified by their length or their age (if otolith measurements are available). As one of the key functions of coastal and estuarine ecosystems is to provide nursery habitats for many commercial fish species and invertebrates (Henriques et al. 2008), the juvenile-based metrics aim, inter alia, at assessing any changes affecting the recruitment in a given fish population. Although that family of metrics is not regularly used as fish indicators in coastal-estuarine communities studies (Le Pape et al. 2003; Neuheimer and Taggart 2007). 


\section{Population-based metrics}

The second organizational level refers to metrics describing the state and the dynamics of single populations of the key species. The commonly used metrics referring to size, such as mean size and length-frequency distributions, are to a certain extent omitted in this paper. Although size is considered as one the most informative traits of an organism, reflecting its living conditions (habitat, species interactions, pressures), it is very unlikely that the size-based metrics at population level are the most relevant metrics assessing changes in coastal and estuarine ecosystems. These ecosystems are mainly characterized by small-sized individuals or small-sized fish species (Rochet et al. 2005; Mouillot et al. 2006), and the fishing protocols (e.g. using bottom trawls with fine mesh size) developed in these ecosystems are often selective in relation to size and/or to species (guild-selective). As a consequence, size-based metrics based on catch sampling may be inappropriate as populationlevel metrics; however, they might be appropriate when focused on a single size-class, such as the juvenile-based metrics.

\section{Community-based metrics}

The third organizational level addresses the metrics referring to fish communities, classified into two groups:

a. Taxonomic metrics (structural). Diversity metrics, such as the Simpson diversity index or its taxonomic generalization $\left(\Delta, \Delta^{*}, \Delta+\right.$; Clarke and Warwick 1998), have been successfully used to assess human impacts in coastal and estuarine ecosystems (Elliott and Dewailly 1995; Clarke and Warwick 1999).

b. Non-taxonomic metrics (functional). Coastal and estuarine ecosystems are essential habitats for resident fish species and transitory key habitats for many marine and freshwater fish species (Gili 2002). Both groups of species are highly dependent on estuaries to complete their life-cycle, and they are most susceptible to being affected by any degradations of these ecosystems (Harrison and Whitfield 2004). Non-taxonomic metrics encompass the functional aspects (e.g. feeding guilds, ecological guilds) of coastalestuarine fish communities and include total abundance or the functional guilds classification proposed by Elliott and Dewailly (1995) and Elliott et al. (2007). Grouping species in functional guilds also simplifies species-rich communities and provides indicators that may be used to compare geographically distant fish communities (Lobry et al. 2003).

\subsubsection{Component 2: combining the metrics}

The characterization of the ecological status of a coastalestuarine ecosystem is a truly multivariate issue. Single descriptors can neither tackle the complexity of the entire system nor be specific to the multiplicity of pressures. Consequently, selected indicators have to be assembled into frameworks within which they can be aggregated and combined (Cury and Christensen 2005). Classical multivariate analysis combining several biological metrics can thus be used to describe ecological patterns which can be considered (e.g.
Gilliers et al. 2006; Thiel et al. 1995) in relation to environmental factors or human-induced pressures. However, in order to satisfactorily assess the ecological status of an ecosystem, it is necessary to integrate several descriptors in a robust and as comprehensive way as possible (Link 2005). In the French approaches, two main methods have been used to combine different metrics in a system.

\section{Aggregation}

The first method consists in aggregating the metrics into a single multi-metric index (MMI). This concept, first introduced as the indicator of biotic integrity (IBI) by Karr (1981), is widely applied in the implementation of the European Water Framework Directive (EU, 2000). MMIs are typically multiscale indicators integrating information on species composition, community structure and ecological function (Cairns et al. 1993), discriminating sites with contrasting degrees of deterioration (sensu Karr 1981, but see Hugues et al. 1998 and Breine et al. 2007). Although both the MMIs and the individual metrics composing them are commonly correlated with a specific stress, the MMIs are often considered as better indicators of habitat quality than any of the individual metrics selected for their construction (Deegan et al. 1997), especially when assessing areas under multiple pressures.

\section{Synoptic table}

To circumvent the methodological problem of aggregating the metrics, one could consider a set of metrics, representing them individually, without computing an integrated value. The different metrics can be considered as different indicators that can be organized on a synoptic table or "dashboard" (Clua et al. 2005). Values or trends of each metric can be interpreted separately in relation to basic ecological and/or fisheries theory or on common sense (Rochet et al. 2005). The fisheries indicators computed by ICES working groups for stock assessments are a good example of multiple indicators dashboard in which each indicator is interpreted separately in relation to fisheries theoretical knowledge. In that example, the formulation of the final diagnosis on the condition of the stock and the management advice takes into account the values or trends of all the indicators. As in the MMI approach, the "dashboard" diagnosis requires a predefined framework to interpret the combination of the information provided separately by each indicator in order to reach the overall diagnosis. The easiest way is to list all the metrics, interpret the values in relation to theoretical elements or empirical evidences and then balance the positive and negative evaluations to establish a diagnosis. Decision rules for the balance can be of several forms: a simple balance, in which positive and negative evaluations are counted, or a "one out - all out" approach, in which a single negative evaluation leads to an overall negative diagnosis. Another, more complex way is to combine selected sets of indicators using a suite of "diagnosis tables" and "decision trees" (Fletcher et al. 2002), whose interpretation requires a conceptual framework relying "on qualitative expectations anchored in ecological theory" (Rochet et al. 2005).

Dashboards might be more useful when the interpretation of the metrics is difficult, i.e. signalling a poor indicator, when there is no quantitative description of a reference state or when 
natural variability is particularly high. When strong scientific knowledge is lacking, decision rules can be empirically developed (e.g. using expert and traditional knowledge). However, one could argue that, in this case, the potential bias in elaborating an overall diagnosis might be comparable to that involved in aggregating the metrics into an MMI.

\subsubsection{Component 3: types of analyses}

Indicators are now widely used by both scientists and stakeholders, and there is a large literature on what is appropriately defined as a good indicator (Rice 2003). An obvious requirement in our case is that it responds primarily to the anthropogenic activity being managed and is sensitive enough to reflect the impact of the activity or the responses to management action (Greenstreet and Rogers 2006). The indicator approach often refers, more or less explicitly, to the DPSIR conceptual framework ${ }^{1}$. It assumes cause-effect relationships between interacting components of a particular system. It also assumes a reliably reactive behaviour of the indicator to the changes of the variable it tracks or to the driver affecting such variable. The response of a metric to a given pressure or set of pressures can be examined either in a direct or indirect analysis (Fig. 1).

\section{Direct analysis}

In the direct analysis the known cause-effect relationship between the metrics' values (e.g. fish abundance) and the specific pressure (e.g. fishing effort) is directly assessed using quantitative statistical methods. This could be considered as a part of a DPSIR approach in which the pressure (e.g. fishing effort) and the Impact (e.g. low abundance) would be responsible for the State of a fish community as expressed by a metric. This leads to the development of models that, in brief, could be named Pressure-Impact models (Wasson et al. 2005). For example, in such models, a pressure must be quantified directly (e.g. in terms of fishing effort) or using a proxy (e.g. the number of trawlers) or an index (e.g. number of trawlers relative to their number in 1975) (e.g. Courrat et al. 2009). As usual, the statistical power of such models is highly dependant on (1) the number of observations and (2) the precision and accuracy of the pressure index. Actually, however, the evaluation of individual metrics, if at all performed, is rarely reported (Hughes et al. 1998).

\section{Indirect analysis}

In an indirect analysis the relationship between the metrics and the pressure is not quantitatively measured but either inferred from the comparison of the trends or based on known relationships in the literature. The temporal or spatial evolution of the metric (e.g. fish abundance) is described using most commonly quantitative methods to analyse time trends

\footnotetext{
1 The driving forces, pressures, states, impacts, responses (DPSIR) model adopted by the European Environment Agency (EEA 1999 ) is an extension of the so-called pressure-state-response (PSR) model developed by the Organisation for Economic Co-operation and Development (OECD).
}

(Désaunay et al. 2006; Lobry et al. 2003) or spatial gradients (Elliott and Dewailly 1995). Concomitant trends are looked for in a given pressure (e.g. fishing effort), which could explain the observed pattern in the metric (an example can be found in Désaunay et al. 2006). Similarity in the direction of the metric and the presumed pressure trends is considered as a sufficient validation of the indicator relevance (e.g. Coates et al. 2007). This type of analysis is qualified as "indirect" because the relationship between the metric and the pressure is not being tested but deduced from the co-evolution of the metric and the pressure and thereby indirectly established.

\subsection{Description of the two approaches used to assess the ecological status of coastal-estuarine ecosystems}

As mentioned earlier, the Vilaine estuary is used as a case study to illustrate the typology and compare the existing approaches. Two approaches are presented. Each approach can be viewed as a combination of the three dimensions presented in Figure 1. The first approach (called hereafter the "temporal trend" approach) combines several metrics (at the subpopulation, population and community levels) in a "dashboard" to assess indirectly the relationship between the metrics and the pressures using time-trend analysis in the coastal area. The second approach (MMI approach) aggregates several metrics (community and functional) using an integrative method assessing directly the relationship between the metrics and a proxy of anthropogenic disturbances in the estuary (i.e. pollution).

\subsubsection{Time-trend approach}

The time-trend approach was initially developed by Rochet et al. (2005) to measure fishing impact at the population and community levels in continental shelf communities of the French Atlantic and English Channel coasts. In the present study, the approach has been adapted from and can be summarized in three steps as follows.

First, yearly indicators are calculated, and linear trends are estimated for each indicator. Multiple trends in several indicators are combined to elaborate a diagnosis of the fishing impact (or anthropogenic pressure) on the monitored fish communities. That diagnosis is notably based on a reference state of the ecosystem defined at the beginning of the data series. Since the reference state of the ecosystem is often not known, expert knowledge and published information are used to determine an "initial state". For the present case study, the initial state of the bay of Vilaine was determined after Rochet et al. (2005) as not strongly impacted, principally on the basis of the decline of the shrimp fisheries in the early 1980s and the moderate decline in fish species of commercial interest. They used the following criteria to define the initial state: communities with several overexploited commercial stocks or subject to a high fishing effort or destructive fishing methods were considered as "impacted", whereas communities where those with none of these characteristics were considered as "non-impacted". The directions of the combined trends are thereafter assessed in relation to that initial state. 
Table 2. Trend results for the 9 metrics used in the time-trend approach. Trends were assessed by simple linear regression analyses. *: significant at $\alpha$ level $<0.05$.

\begin{tabular}{lll}
\hline Metric & Test result & Expected trend \\
\hline $1 . \ln (N)_{(G 0) i, t}$ & No significant trend & Decrease \\
\hline 2. $L_{(G 0) i, t}$ & ${ }^{*} 1$ significant increasing trend: S. solea & Decrease \\
3. $L_{i, t}$ & ${ }^{*} 2$ significant increasing trends: P. platessa C. lyra & Decrease \\
4. $B_{i, t}$ & No significant trend & Decrease \\
Diversity indices & & \\
5. Pielou's evenness $(J)$ & ${ }^{*}$ Significant decreasing trend & Decrease \\
Taxonomic diversity indices & & \\
6. Taxonomic distinctness $\left(\Delta^{*}\right)$ & ${ }^{*}$ Significant decreasing trend & \\
Non-taxonomic diversity indices & & Decrease \\
7. $N$ Dep & No significant trend & \\
8. $R_{\text {Dep/Indep }}$ & No significant trend & Decrease \\
$9 . F G_{\text {Simpson }}$ & No significant trend & Decrease \\
\end{tabular}

Second, once all the trends are estimated for all the indicators, the combined trends of the indicators are interpreted. This is done by pairing indicators at the population and community levels in diagnostic tables. There are as many diagnostic tables as there are possible combinations of indicators, and their interpretation is made according to ecological theory and common sense. For instance, if the average length of the juveniles within a population decreased, and its abundance also decreased, this means that there were fewer recruits of smaller size. Several causes (or pressures) could explain that situation. The observation could reflect increased mortality (fishing or natural mortality or both) concomitant with decreased recruitment. It could also reflect lower growth, which might in turn result from changes in the environment (food, temperature, competition) or late spawning. Following the example, the diagnostic table from the combination of the two indicators (e.g. average length and abundance of juveniles) is filled with trends of the juveniles of all the studied populations (e.g. Solea solea, Pleuronectes platessa, etc.). The diagnostic tables are filled that way for the subpopulation (juvenile-based) and population indicators, whereas the community indicators are analysed jointly using diagnosis trees (Fig. 3b). In these trees, one indicator trend is examined at each knot, and a branch is selected depending on the test result. Cells are shaded if it is suspected that one of the potential mechanisms for the trend is related to an anthropogenic pressures (i.e. fishing and pollution) and left clear if the trend is stationary (Rochet et al. 2005).

Third, when all the tables have been filled, a test procedure (e.g. multinomial and binomial tests in the present case) is followed to assess probabilities for each trend combination. From these probabilities, a final diagnosis is made conventionally, agreeing that, if one level of organization (juvenile, population or community) is found to be deteriorating, the whole ecosystem is considered to be deteriorating.

The interpretation frameworks are the key component and the major contribution to that approach. Since the potential causes (or pressures) are assessed each time a combination of indicators is examined, the crossing of this information will likely help to disentangle the potential mechanisms involved in the ecosystem diagnosis (i.e. whether the system is impacted or not and what are the potential causes). In communities subject to multiple pressures, such as those encountered in coastal and estuarine ecosystems, a similar interpretation framework is needed to help eventually distinguish the impacts of natural variations from those of anthropogenic stresses (Elliott and Quintino 2007).

\section{Modifications from Rochet et al. (2005)}

The indicators used by Rochet et al. (2005) were well suited for offshore communities responding essentially to fishing pressure. However, some of them are less suitable for coastal and estuarine fish communities that react to fisheries as well as to other anthropogenic pressure such as pollution. As a consequence, we compiled different metrics thought to be "more relevant" to assess pollution-related changes in these communities (Table 1).

The data used in the time-trend approach came from the coastal trawl surveys for juvenile flatfish species conducted by Ifremer in the Bay of Biscay between 2000 and 2005. These nursery-dedicated surveys were carried out from the end of August to the end of October because earlier studies had found that this period, coinciding with the end of the growth phase of juvenile flatfish, is suitable period for their capture, providing consistent estimates for the 0-group fish (in short, G0; Dorel et al. 1991). Surveys were conducted using a sampling design stratified by depth strata (ranging from 5 to $35 \mathrm{~m}$ ) and sediment types. Sampling was done using a 2.9-m wide and 0.5-m high beam trawl with a $20-\mathrm{mm}$ stretched-mesh net in the cod-end. Over the six years of sampling, a total of 195 hauls were made at a speed of 3 knots, for 15 minutes, covering a mean surface of $3790 \mathrm{~m}^{2}$ (standard deviation $\left.=225 \mathrm{~m}^{2}\right)$.

In this approach, nine metrics were computed (Table 2) at juvenile level (on 7 species), population level (on 18 species) and community level (on 28 species). The related lists of species are given in Table 3. Metrics at these different levels of organization were computed using different sets of species because each metric requires specific information that is often not available for all the species. For instance, the nurserydedicated surveys are routinely measuring length frequencies 
Table 3. Fish species used in the computation of the juvenile, population, and community metrics.

\begin{tabular}{|c|c|c|c|c|c|c|}
\hline \multirow[t]{2}{*}{ Species } & \multirow[t]{2}{*}{ Family } & \multicolumn{2}{|c|}{ Estuary-dependent } & \multicolumn{3}{|c|}{ Biological organization level } \\
\hline & & & & Juvenile & Population & Community \\
\hline Anguilla anguilla & Anguillidae & & No & & & $\mathrm{x}$ \\
\hline Arnoglossus laterna & Bothidae & & No & $\mathrm{x}$ & $\mathrm{x}$ & $\mathrm{x}$ \\
\hline Buglossidium luteum & Soleidae & & No & & $\mathrm{x}$ & $\mathrm{x}$ \\
\hline Callionymus lyra & Callionymidae & & No & & $\mathrm{x}$ & $\mathrm{x}$ \\
\hline Chelidonichthys gurnardus & Triglidae & Yes & & & & $\mathrm{x}$ \\
\hline Chelidonichthys lucernus & Triglidae & & No & & $\mathrm{x}$ & $\mathrm{x}$ \\
\hline Ciliata mustela & Gadidae & Yes & & & & $\mathrm{x}$ \\
\hline Dicentrarchus labrax & Moronidae & Yes & & & $\mathrm{x}$ & $\mathrm{x}$ \\
\hline Dicologlossa cuneata & Soleidae & Yes & & $\mathrm{x}$ & $\mathrm{x}$ & $\mathrm{x}$ \\
\hline Gobius niger & Gobiidae & & No & & $\mathrm{x}$ & $\mathrm{x}$ \\
\hline Hippocampus hippocampus & Syngnathidae & Yes & & & $\mathrm{x}$ & $\mathrm{x}$ \\
\hline Limanda limanda & Pleuronectidae & & No & & & $\mathrm{x}$ \\
\hline Merluccius merluccius & Merluccidae & Yes & & & $\mathrm{x}$ & $\mathrm{x}$ \\
\hline Merlangius merlangus & Gadidae & Yes & & $\mathrm{x}$ & $\mathrm{x}$ & $\mathrm{x}$ \\
\hline Microchirus variegatus & Soleidae & Yes & & & & $\mathrm{x}$ \\
\hline Mullus surmuletus & Mullidae & Yes & & $\mathrm{x}$ & $\mathrm{x}$ & $\mathrm{x}$ \\
\hline Phrynorhombus norvegicus & Scophthalmidae & Yes & & & & $\mathrm{x}$ \\
\hline Platichthys flesus & Pleuronectidae & & No & & & $\mathrm{x}$ \\
\hline Pleuronectes platessa & Pleuronectidae & & No & $\mathrm{x}$ & $\mathrm{x}$ & $\mathrm{x}$ \\
\hline Pomatoschistus minutus & Gobiidae & Yes & & & $\mathrm{x}$ & $\mathrm{x}$ \\
\hline Scyliorhinus canicula & Scyliorhinidae & & No & & & $\mathrm{x}$ \\
\hline Solea solea & Soleidae & Yes & & $\mathrm{x}$ & $\mathrm{x}$ & $\mathrm{x}$ \\
\hline Sparus auratus & Sparidae & Yes & & & & $\mathrm{x}$ \\
\hline Spondyliosoma cantharus & Sparidae & & No & & $\mathrm{x}$ & $\mathrm{x}$ \\
\hline Trachurus trachurus & Carangidae & Yes & & & $\mathrm{x}$ & $\mathrm{x}$ \\
\hline Trisopterus luscus & Gadidae & & No & $\mathrm{x}$ & $\mathrm{x}$ & $\mathrm{x}$ \\
\hline Trisopterus minutus & Gadidae & & No & & $\mathrm{x}$ & $\mathrm{x}$ \\
\hline Zeus faber & Zeidae & & No & & & $\mathrm{X}$ \\
\hline
\end{tabular}

of commercial fish species such as flatfish (e.g. Solea solea) but not gobies (e.g. Pomatoschistus sp.) and therefore gobies could not be included in the computation of the juvenile-based metrics.

\subsubsection{Multi-metric index, MMI approach}

The EU Water Framework Directive (EWFD) has introduced the use of fish indicators to assess and monitor the ecological status of estuaries through fish assemblages. The EWFD clearly underlines the multivariate aspect of the issue by identifying several dimensions (diversity, abundance and age) that need to be taken into account for the diagnosis. Several approaches have been developed in order to construct MMIs all around Europe (e.g. Borja et al. 2004, 2009; Breine et al. 2007; Coates et al. 2007) and in North America (Deegan et al. 1997; Hughes et al. 1998) or South Africa (Harrison and Whitfield 2004, 2006). Each MMI results in a specific combination of methodological choices at various steps of the construction. Some of these choices are summarized in Table 4 and range from the scale at which metrics are computed to the method used to combine the selected metrics.

A scientific project, set up by the French Water Agencies and the French Ministry in charge of ecology (LITEAU research program), was devoted in 2006 to the definition of a MMI to assess the ecological status of transitional waters for the implementation of the EWFD in France. Based on a set of sampling data from surveys conducted on 24 estuaries (Courrat et al. 2009 for the description of the sampling protocol), 22 metrics were calculated. These metrics refer to ecological guilds associated with various functions of estuaries. They were related to indices of pollution by heavy metals and organic contaminants. Indices of pollution were computed as follows. First, contamination values measured on mussels or oysters were available for each estuarine area since 1979 through the French national marine environment quality network. A principal component analysis (PCA) was computed on contamination data, and pollution indices were constructed using coordinates of each site on the PCA loadings. These indices were used as proxies for the anthropogenic disturbances impacting estuaries. Second, generalized linear models (GLM) were used to analyse the metrics' apparent response 


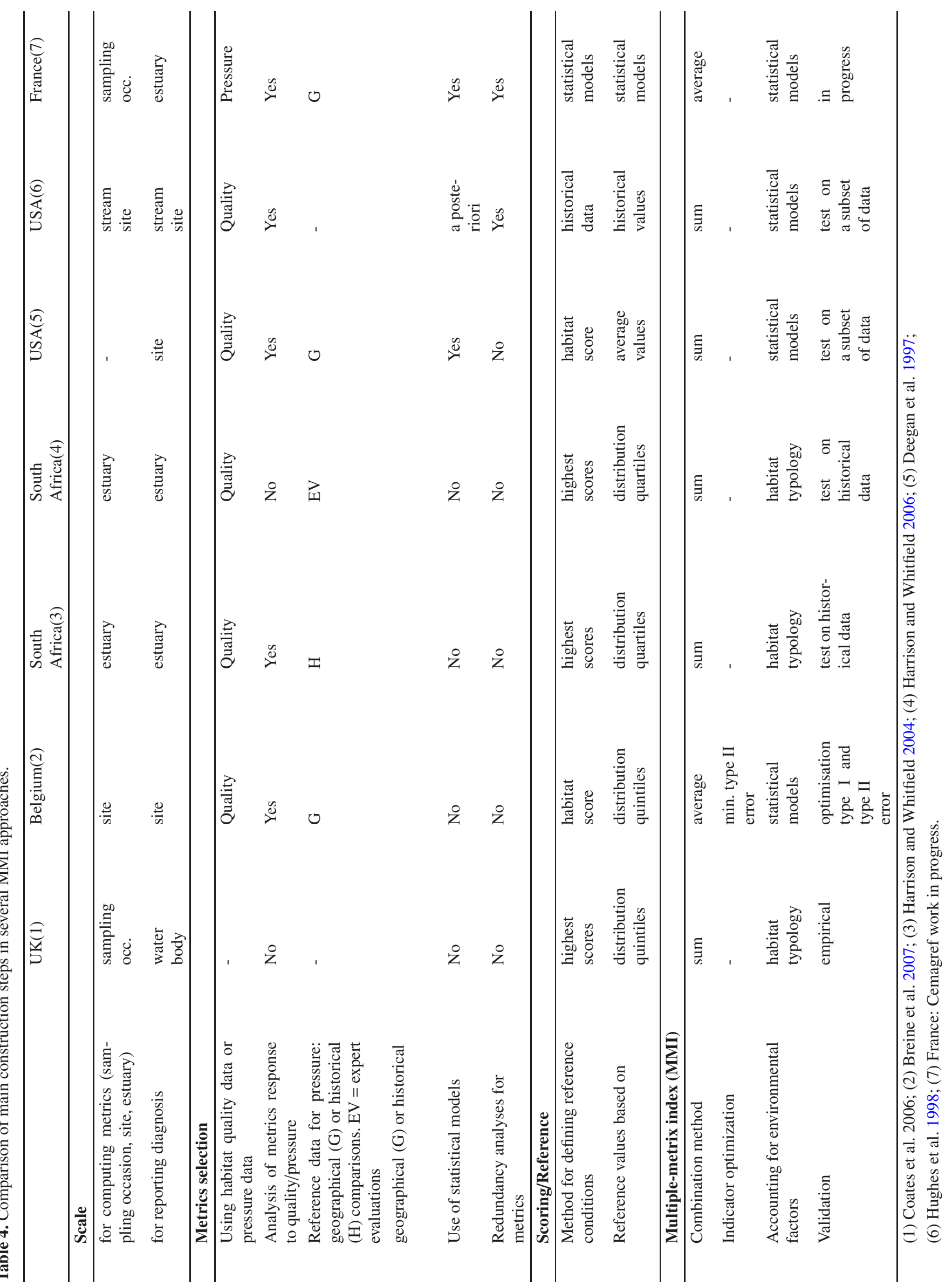




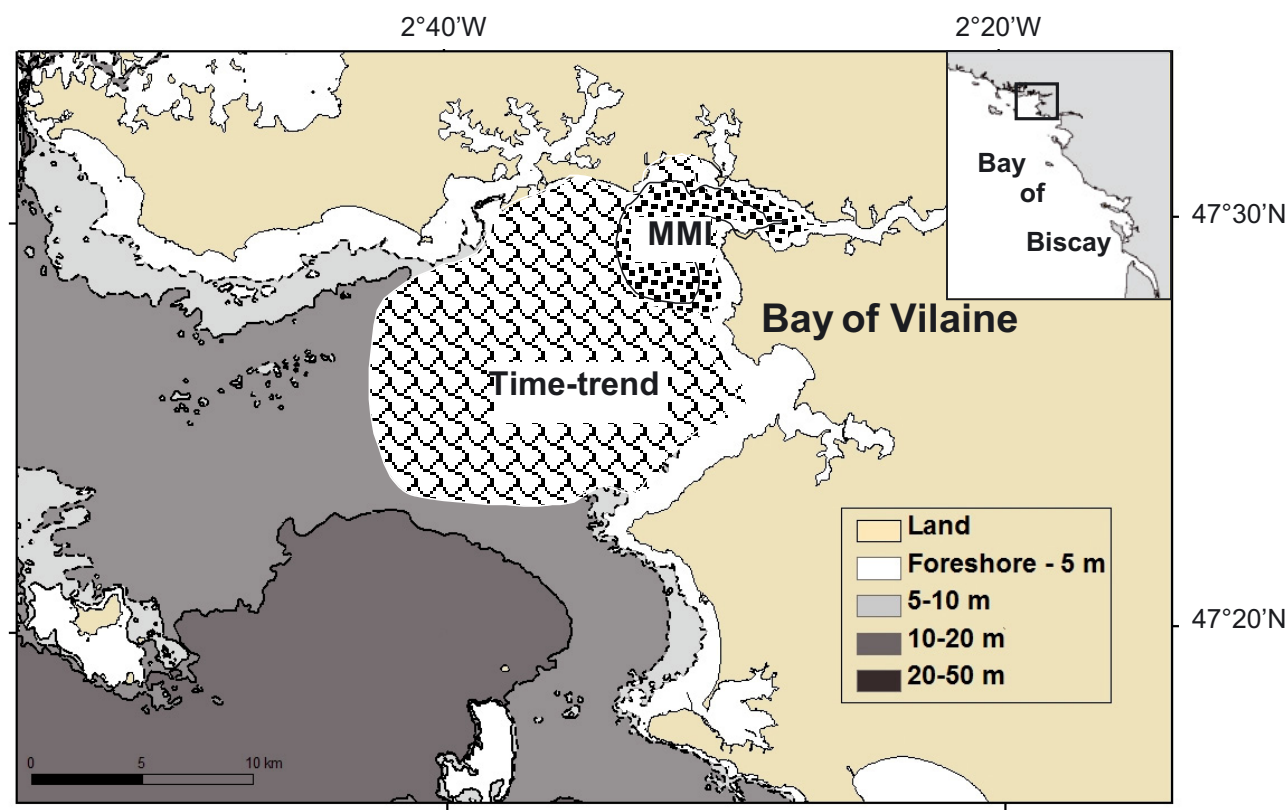

Fig. 2. Location of the Bay of Vilaine (southern Brittany, France). Geographic extensions of the Ifremer dataset used in the time-trend approach, covering the nearshore outer part of the estuary where bathymetry goes up to $40 \mathrm{~m}$ and salinities reach $35 \mathrm{mg} \mathrm{L}^{-1}$ and the European Water Framework Directive dataset integrating marine to freshwater conditions $\left(<5 \mathrm{mg} \mathrm{L}^{-1}\right)$.

to pollution pressure, and only metrics showing a statistically significant relationship with pollution proxies were considered as relevant indicators of pollution.

In the LITEAU project, preliminary analyses were conducted on a subset of 13 estuaries (all sampled in 2006) and concerned two fish metrics: abundance and species richness of marine juvenile migrant fishes, both of which were considered as representative metrics for the estuarine nursery function (Courrat et al. 2009). The two fish metrics displayed a significant response to a gradient of estuarine contamination thus providing a useful tool to assess habitat quality for juvenile fishes, as well as the general ecological status of estuaries, for the purpose of the EWFD (Basset and Abbiatti 2004). The first results concerned only detection of pollution disturbance, but the aim was to develop a general methodology which could be used for assessing the fish response to various anthropogenic pressures. Further analyses (S. Delpech, pers. comm.), prompted by the work of Courrat et al. (2009), were conducted at the French institute for agricultural and environmental engineering research (Cemagref) to select a larger number of metrics reflecting gradients of heavy metals and organic pollution and combine them in a multi-metric indicator.

The GLMs used for selecting the relevant metrics are then used to predict the values of each retained metrics in relation to the pollution states: heavily, moderately and lightly polluted. The examination of confidence intervals for these three values sets class boundaries for each metric. Metric values calculated through sampling data are then compared for each selected metric and each estuary to classify boundary values estimated using GLM predictions. This allows computing a score for all the metrics depending on the class the calculated value falls into. An overall score is obtained by averaging the scores calculated for all the metrics. As all estuarine zones were not sampled in the same periods, class boundary settings are computed using data from the subset of the 13 estuaries that were sampled in 2006 (calibration data) and then applied to assess all the 24 estuarine systems (including those that were sampled in 2007 - validation data). Reference conditions values will be computed by extrapolation of the statistical models to unpolluted conditions (i.e. by setting pressure index value to " 0 " in the model).

\subsection{Case study: the Vilaine estuary}

The bay of Vilaine is located along the French Atlantic coast in southern Brittany (Fig. 2). The bay is characterized by an open, shallow, muddy estuarine area under the direct influence of freshwater runoff (Gilliers et al. 2006). The Vilaine is one of the longest rivers in France $(225 \mathrm{~km})$, with a catchment area of nearly $10400 \mathrm{~km}^{2}$, draining one-third of Brittany waters. As Brittany is mainly devoted to agricultural activities, the river is subject to high nutrient concentrations and potential contamination by pesticides (Forget et al. 2003). Nutrient loads and increased sedimentation rates, due to the construction of the Arzal dam (12 km from the estuary's mouth), are the main factors involved in hypoxic/anoxic events in summer (Guillaud et al. 2008). The bay of Vilaine is also characterized by inshore fishing activities, principally by bottom trawlers and potters (Léauté 2006).

\section{Results}

\subsection{Time-trend approach}

Four metrics, of the nine calculated, displayed significant linear time-trends (Table 2), either increasing (log-transformed 


\begin{tabular}{|l|c|c|c|}
\cline { 2 - 4 } \multicolumn{1}{c|}{$(\mathrm{a})$} & \multicolumn{3}{c|}{$\ln (\mathrm{N})_{(\mathrm{G} 0)} i, t$} \\
\hline$\overline{\mathrm{L}}(\mathrm{G} 0) i, t$ & Increase & Stationary & Decrease \\
\hline Increase & & & \\
\hline Stationary & 1 & 6 & \\
\hline Decrease & & & \\
\hline
\end{tabular}

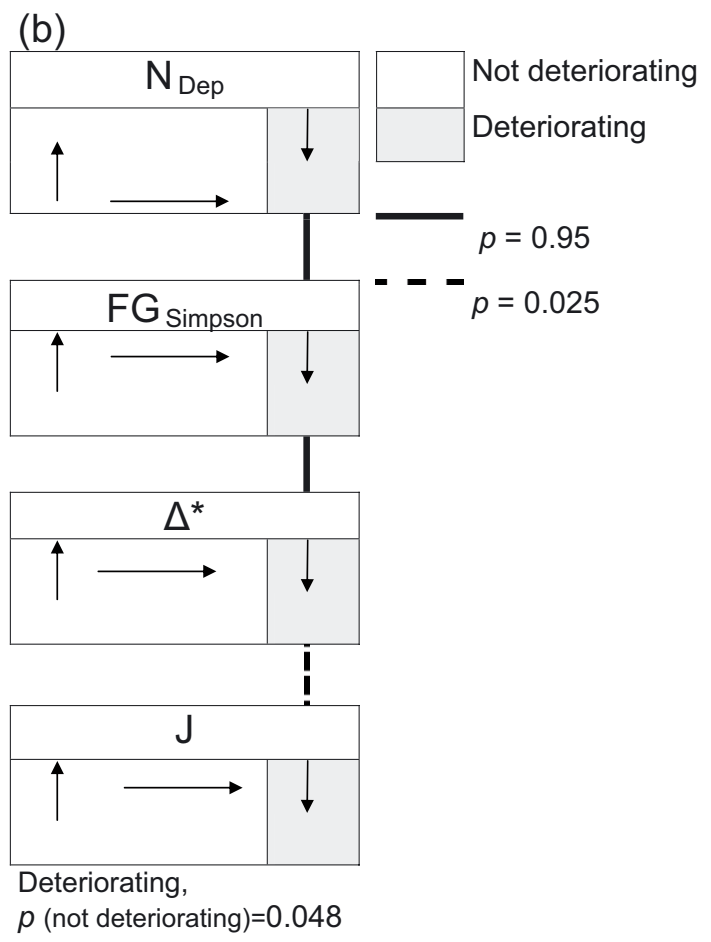

Fig. 3. Results from the time-trend approach displaying the combination of indicators to assess ongoing changes in fish communities. Cells are shaded when the combination of metrics indicates that the community is heading towards an undesirable state. (a) Combined trends for the juvenile-based metrics (average length and natural logarithm of the zero age group abundance at time t (year)). (b) Diagnosis tree trends in community metrics (see methods, and Rochet et al. 2005 for details). Codes detailing each metric are defined in Table 1.

abundance of the Solea solea young-of-the-year (G0) and Pleuronectes platessa and Callyonimus lyra populations) or decreasing (Pielou's evenness index and taxonomic distinctness). In reference to the selected "initial state" (i.e. not strongly impacted), the juvenile-based and community-based metrics were respectively combined into diagnosis frameworks: a matrix for population metrics (Fig. 3a) and a diagnosis tree for community metrics (Fig. 3b). The matrix indicated that the average length of the juveniles of the seven fish species remained stationary between 2000-2005 (i.e. no values in shaded cases). The log-transformed abundance of the juveniles was also stationary, except for one species which increased. At the juvenile and population levels, the conclusion is that the system remained "non-impacted". On the other hand, when the trends of the community indicators are analysed using the diagnostic tree, the diagnosis suggests a "deteriorating" state $(p=0.048)$. This deteriorating state is reflected in the decreasing relative abundance of estuary-dependent taxa
$\left(N_{\text {dep }}\right)$ and diversity of trophic and ecological guilds (first two cases in the tree; Fig. 3b). When combined into a final diagnosis, these elements lead to the conclusion that the fish community from the bay of Vilaine is in a deteriorating state. However, it is important to recall that, as the approach relies on an indirect level of analysis (Fig. 1) and the interpretation frameworks are still being improved, it is actually impossible to correlate the deteriorating state to any human-induced stresses (nor fishing or pollution).

\subsection{MMI approach}

At the time this paper was written, preliminary results were available in technical reports; thus, an extrapolation of methods developed by Courrat et al. (2009) and S. Delpech (pers. comm.) was applied on a larger set of estuarine areas. The Vilaine estuary was included into the large set of 24 estuaries but not into the subset of 13 estuaries used for calibration. A total of 21 and 23 beam-trawl hauls were conducted in spring and autumn 2007 respectively, 85\% of them in polyhaline and marine conditions. Results show that the Vilaine's scores for all the selected metrics are amongst the highest of all the estuaries included in the analysis. This indicates that, in relation to contamination, the Vilaine estuary can be classified amongst the estuarine areas with the highest ecological quality status. These preliminary results have to be considered with caution, as the indicator is not yet validated and was computed using only one year of sampling data. Further analyses are in progress to validate the MMI, and other surveys will be conducted in the next few years to account for natural variability in the environment and determine if natural noise could hide the contamination signal.

\subsection{Integration of time-trend and MMI approaches}

The two approaches led to two different diagnoses of the ecological status of the Vilaine. In addressing two different ecological domains -coastal and estuarine- of the Vilaine ecosystem, the two approaches dealt with two different sets of ecological components. This was notably observed in the choice of the functional metrics. The proportion of estuarineresident taxa is generally used in fish-based assessment of ecological quality of estuaries (Breine et al. 2007; Elliott et al. 2007) and was tested in the MMI approach. That metric was slightly adapted in the time-trend approach to further include other estuarine-dependent groups such as the juvenile migrants, as the sampling (Fig. 1) was not limited to the estuary but covered both the bay and the mouth of the estuary. The time-trend approach included a larger spectrum of (marine) taxa that use the estuary to complete their life cycle than the MMI. Concurrently, the time-trend approach included a larger array of organisation levels and might have captured the many dimensions of the Vilaine estuary.

Metrics used in the time-trend approach were also indirectly related to fishing pressure and other potential stresses affecting the recruitment and structure of the Vilaine fish community, whereas metrics used in MMI approach were mainly focusing on heavy metal and organic contamination. 
When analysed together, these results may suggest that the Vilaine ecosystem (bay and estuary) is under human-induced stresses but that the pressures affecting the fish communities are not likely to be related to the heavy metal and organic contaminations.

Comparison with other studies that assessed the ecological status of the bay of Vilaine can also be made. The study conducted by Rochet et al. (2005) included an analysis of the fish community of the bay of Vilaine. The data on which they conducted their analysis were, however, slightly different than those used in the present work. They used an earlier and longer time series (1982-2002) and a different set of indicators. Despite these differences, the two studies agree on the undesirable trend (i.e. deteriorating) observed. The final diagnosis made by Rochet et al. (2005) was mainly driven by the populationbased indicators, whereas the final diagnosis in the present work is principally influenced by the community-based indicators. Unfortunately, we could not compute our community indicators on the time series used by Rochet et al. (2005) because the data used in their study (1982-2002) came from a sampling protocol that only surveyed commercial species. Our indicators required data on all the fish species captured in a haul, i.e. irrespective of whether they are of commercial interest or not. Taken together, the two diagnoses are complementary and may suggest potential transfer of undesirable impacts from population to community levels. This conclusion will obviously need more analyses to be confirmed.

\section{Discussion}

\subsection{Comparison of the two approaches}

The Vilaine estuary offered a good case study to compare the two approaches. It is one of the French estuaries targeted in the European Water Framework Directive and, as an important nursery ground for many commercial fish species, it is one of the rare coastal areas that have been and are still being surveyed every year by Ifremer. The fact that the MMI used the data acquired for the EWFD while the time-trend used the data from the Ifremer surveys implies that the two methods were conceptualised and developed in different contexts: (i) an "environmental" context, to satisfy the prerequisites of the EWFD; and (ii) a "fishery" context, to satisfy some of the requirements of the Marine Strategy Framework Directive. The types of data and thus the reference required by each approach are also different. The time-trend approach is based on a historic reference and necessitates temporal series, whereas the MMI is based on a spatial (or geographic) reference requiring data from different ecosystems with contrasting situations in relation to the pressure under study (see below regarding each approach). Considering these characteristics, the two approaches are evidently different but they can also be considered as complementary when addressing a common question. Ideally, the use of both approaches combined would enhance the description and comprehension of the ecosystem but, in practice, the data are rarely sufficient to do so.

The two approaches rest on fundamentally contrasting premises. As illustrated in Figure 1, the two approaches reflect different choices in terms of organisational level, analysis and method used to combine the metrics. The greater discrepancies lie in the combining method and, to a certain extent, in the type of analysis used in the two approaches. The type of analysis seems to be less important because, once a metric has been directly correlated with a pressure, it becomes an "indicator" that can be computed in similar ecosystems and may be adequate (with due verification) to assess the impact of that pressure. If combinations of these indicators are to be used in a time-trend approach or any "dashboard" as it is in Rochet et al. (2005) for the fishing impact, then the indirect analysis can be switched to a direct one. Also, when considering a set of metrics or indicators to be combined into an MMI or a "dashboard", the direct and indirect analyses can be jointly used to analyse the response to a given pressure. For instance, the response to a pressure (e.g. contamination) can be assessed directly and separately for a set of specific metrics (such as abundance or diversity of selected populations or guilds) included in an MMI. Simultaneously, the response to the same pressure can be assessed indirectly for the (aggregated) overall index.

The differences between the methods used to combine the metrics are more critical. The two approaches are based on contrasting assumptions, particularly concerning the reference level assessment, a crucial element in the development of indicator systems. In both approaches the reference state was initially unknown but they differed in the nature of the reference finally selected in the following way: (i) the definition of the reference value, i.e. experience-based and agreed to by experts in time-trend versus the virtual maximum value in the MMI approach; (ii) the comparison with what the reference is made, i.e. the target community (i.e. with itself) in time-trend versus other communities (from different estuaries) in the MMI approach and (iii) the number of references, i.e. a single reference in time-trend versus multiple ones in the MMI approach.

Various methods for aggregating metrics can be used: weighted or non-weighted sum, arithmetic or geometric mean of the metrics' scores. In most cases, authors use a simple sum (Karr 1981; Deegan et al. 1997; Hugues et al. 1998; Harrison and Whitfield 2004, 2006; Coates et al. 2007) or average (Breine et al. 2007) of the scores without any weighting of the values. This is probably the simplest way to combine values with less preconceptions. However, not weighting the metrics when aggregating them into an overall index implies also an assumption: that all metrics have the same significance when evaluating the ecological state of the fish community. The choice of multiplying the metrics scores instead of summing them is a way to adopt, to a certain extent, a precautionary principle. Indeed, when metrics scores lie between 0 and 1 , a low metric score has a great effect on the total value of the indicator and can "penalize" the result of the biological assessment. The main inconvenience of fish MMI is that the method used to aggregate the metrics is usually empirical and not founded on any ecological assumptions. Most of the time, the choice of the method is not even argued. In most cases, it is simply not possible to point out specific ecological functions and thus weight the metrics in relation to their capacity for characterizing ecological status of the community. Contrary to fish communities, for which theoretical elements assessing how communities respond to perturbations are often missing, 
benthic communities are well documented. Justification of the weighting method in such communities is thus based on strong ecological evidences, and useful indicators have indeed been developed (AMBI, marine biotic index; Borja et al. 2000).

\section{Conclusion: emergent characteristics}

The approaches presented here involve an objective selection of methods amongst a large array of methods available for constructing an indicator to assess the ecological status of coastal fish communities. The present paper is not a practical guide on indicators systems development - available in Rice and Rochet (2005) for example - but rather a presentation of the authors" opinion on "critical" elements in constructing such indicators, based on the analysis of a number of research projects undertaken along the French coasts. The paper highlights the fact that, besides their conceptual differences, the approaches presented here have some methodological points of convergence:

1. A will to go beyond structural considerations, integrating functional aspects of fish communities - notably through the use of functional guilds in the indicator;

2. The use of a gradient or contrasting levels of pressure (on a geographical or temporal scale) to increase the power of the indicators to detect perturbed situations from the natural noise;

3. The use of quantitative methods and particularly statistical models in order to increase as much as possible the accuracy of the index, and

4. A certain degree of empiricism (in the use of expert judgement), whatever the combining method used (aggregation or synoptic table and/or the type of analysis).

These points are probably "emblematic" in the construction of an indicator approach in coastal-estuarine ecosystems, considering the inherent multivariate nature of the pressures affecting them.

The development of coastal and estuarine indicators could be improved in two ways:

1. By increasing and focusing efforts on the collection of relevant data on ecological communities and pressures, which can be synthesized in metrics and indices quantifying the cause effect relationships;

2. By developing and adopting methods optimising the integration of expert judgement and other empirical evidence, e.g. through fuzzy logic (Cheung et al. 2005) and Bayesian Belief Networks (Hosack et al. 2008).

Acknowledgements. This study was partly supported by the European program IMAGE and the French research agency (Agence nationale de la recherche) under the project AMPHORE. The authors thank the scientists who contributed to the development of the timetrend and MMI approaches: M.J. Rochet, V. Trenkel, A. Courrat, O. Le Pape, C. Delpech, S. Pasquaud, M. Lepage. They are also grateful to the crews of the R.V. "Gwen Drez" who participated to the time-trend approach sampling cruises conducted between 2000 and 2005. Results from the preliminary multimetric index developed in the Vilaine estuary are part of LITEAU scientific project founded by the French Water Agencies and the French ministry in charge of ecology and coordinated by Cemagref (French institute for agricultural and environmental engineering research). The authors wish to thank all the participant in the project.

\section{References}

Adam S.M. (ed.), 2002, Biological indicators of aquatic system stress. American Fisheries Society, Bethesda, Maryland.

Babcock E.A., Pikitch E.K., McAllister M.K., Apostolaki P., Santora C., 2005, A perspective on the use of spatialized indicators for ecosystem-based fishery management through spatial zoning. ICES J. Mar. Sci. 62, 469-476.

Baird D., Ulanowicz R.E., 1993, Comparative study of the trophic structure, cycling and ecosystem properties of four tidal estuaries. Mar. Ecol. Prog. Ser. 99, 221-237.

Basset A., Abbiati M., 2004, Challenges to transitional water monitoring: ecological descriptors and scales. Aquat. Conserv. Mar. Freshw. Ecosyst. 14, S1-S3.

Borja A., Franco J., Perez, V., 2000, A marine biotic index to establish the ecological quality of soft-bottom benthos within European estuarine and coastal environments. Mar. Pollut. Bull. $40,1100-1114$.

Borja A., Franco J., Valencia V., Bald J., Muxika I., Belzunce M.J., Solaun O., 2004, Implementation of the European Water Framework Directive from the Basque country (Northern Spain): a methodological approach. Mar. Pollut. Bull. 48, 209-218.

Borja A., Ranasingheb A., Weisberg, S.B., 2009, Assessing ecological integrity in marine waters, using multiple indices and ecosystem components: Challenges for the future. Mar. Pollut. Bull. 59, $1-4$.

Breine J., Maes J., Quataert P., Van den Bergh E., Simoens I., Van Thuyne G., Belpaire C., 2007, A fish-based assessment tool for the ecological quality of the brackish Shelde estuary in Flanders (Belgium). Hydrobiologia 575, 141-159.

Cairns J., McCormick P.V., Niederlehner B.R., 1993, A proposed framework for developing indicators of ecosystem health. Hydrobiologia 263, 1-44.

Cheung W.W.L., Pitcher T.J., Pauly D., 2005, A fuzzy logic expert system to estimate intrinsic extinction vulnerabilities of marine fishes to fishing. Biol. Conserv. 124, 97-111.

Clarke K.R., Warwick R.M., 1998, A taxonomic distinctness index and its statistisal properties. J. Appl. Ecol. 335, 523-531.

Clarke K.R., Warwick R.M., 1999, The taxonomic distinctness measure of biodiversity: weighting of step lengths between hierarchical levels. Mar. Ecol. Prog. Ser. 184, 21-29.

Clua E., Beliaeff B., Chauvet C., David G., Ferraris J., Kronen M., Kulbicki M., Labrosse P., Letourneur Y., Pelletier D., Thébaud O., Léopold M., 2005, Towards multidisciplinary indicator dashboards for coral reef fisheries management. Aquat. Living Resour. 18, 199-213.

Coates S., Waugh A., Anwar A., Robson M., 2007, Efficacy of a multi-metric fish index as an analysis tool for the transitional fish component of the Water Framework Directive. Mar. Pollut. Bull. $55,225-240$. 
Costanza R., d'Arge R., de Groot R., Farber S., Grasso M., Hannon B., Limburg K., Naeem S., O'Neill R.V., Paruelo J., Raskin R.G., Sutton P., van den Belt M., 1997, The value of the world's ecosystem services and natural capital. Nature 387, 253-260.

Costanza R., Mageau M., 1999, What is a healthy ecosystem? Aquat. Ecol. 33, 105-115.

Courrat A., Lobry J., Nicolas D., Laffargue P., Amara R., Lepage M., Girradin M., Le Pape O., 2009, Anthropogenic disturbance on nursery function of estuarine areas for marine species. Estuar. Coast. Shelf Sci. 81, 179-190.

Cury P., Christensen V., 2005, Quantitative ecosystem indicators for fisheries management. ICES J. Mar. Sci. 62, 307-310.

Deegan L.A., Finn J.T., Ayvazian S.G., Ryder-Kieffer C.A., Buonaccorsi J., 1997, Development and validation of an estuarine biotic integrity index. Estuaries 20, 601-617.

Désaunay Y., Gue'rault D., Le Pape O., Poulard J.-C., 2006, Changes in occurrence and abundance of northern/southern flatfishes over a 20-year period in a coastal nursery area (Bay of Vilaine) and on the eastern continental shelf of the Bay of Biscay. Scient. Mar. 70 (Suppl. 1), 193-200.

Dorel D., Koutsikopoulos C., Désaunay Y., Marchand J., 1991, Seasonal distribution of youg sole (Solea solea L.) in the nursery ground of the bay of Vilaine (Northern Bay of Biscay). Neth. J. Sea Res. 27, 297-306.

Elliott M., Dewailly F., 1995, The structure and components of European estuarine fish assemblages. Neth. J. Aquat. Ecol. 29, 397-419.

Elliott M., Quintino V., 2007, The Estuarine quality paradox, environmental homeostasis and the difficulty of detecting anthropogenic stress in naturally stressed areas. Mar. Pollut. Bull. 54, 640-645.

Elliott M., Whitfield A.K., Potter I.C., Blaber S.J.M., Cyrus D.P., Nordlie F.G., Harrison T.D., 2007, The guild approach to categorizing estuarine fish assemblages: a global review. Fish Fish. 8, 241-268.

EEA, 1999, State and Pressures of the Marine and Coastal Mediterranean Environment. Environmental Assessment Series. European Environment Agency, Copenhagen.

EU, 2000, Directive 2000/60/EC of the European Parliament and of the Council of 23 October 2000 establishing a framework for Community action in the field of water policy. Official Journal of the European Communities L327, pp. 1-72.

Fletcher R., Chesson J., Fisher M., Sainsbury K., Hundloe T., Smith T., Whitworth B., 2002, National ESD reporting framework for Australian fisheries: the "how to" guide for wild capture fisheries. Fisheries Research and Development Corporation. Canberra, FRDC Project 2000/145.

Forget J., Beliaeff B., Bocquené, G., 2003, Acetylcholinesterase activity in copepods from the Vilaine River estuary, France, as a biomarker of neurotoxic contaminants. Aquat. Toxicol. 62, 195-204.

Gili J.-M., 2002, Towards a transitory or ephemeral key habitat concept. Trends Ecol. Evol. 17, 453.
Gilliers C., Le Pape O., Desaunay Y, Morin J., Guérault D., Amara R., 2006, Are growth and density quantitative indicators of essential fish habitat quality? An application to the common sole Solea solea nursery grounds. Estuar. Coast. Shelf Sci. 69, 96-106.

Greenstreet S.P.R., Rogers S.I., 2006, Indicators of the health of the fish community of the North Sea: identifying reference levels for an ecosystem approach to management. ICES J. Mar. Sci. 63, 573-593.

Guillaud J.-F., Aminot A., Delmas D., Gohin F., Lunven M., Labry C., Herbland A., 2008, Seasonal variation of riverine nutrient inputs in the northern Bay of Biscay (France), and patterns of marine phytoplankton response. J. Mar. Syst. 72, 309-319.

Harrison T.D., Whitfield A.K., 2004, A multi-metric fish index to assess the environmental condition of estuaries. J. Fish Biol. 65, 683-710.

Harrison T.D., Whitfield A.K., 2006, Application of a multimetric fish index to assess the environmental condition of South African estuaries. Estuar. Coasts 29, 1108-1120.

Hénocque Y., Denis J. (Eds), 2001, A Methodological Guide: Steps and Tools Towards Integrated Coastal Area management. Manuals and Guides 42. Intergovernmental Oceanographic Commission of UNESCO, Paris.

Henriques S., Pais M.P., Costa M.J., Cabral H., 2008, Development of a fish-based multimetric index to assess the ecological quality of marine habitats: the marine fish community index. Mar. Pollut. Bull. 56, 1913-1934.

Hosack G.R., Hayes K.R., Dambacher J.M., 2008, Assessing model structure uncertainty through an analysis of system feedback and Bayesian networks. Ecol. Appl. 18, 1070-1082.

Hughes R.M., Kaufmann P.R., Herlihy A.T., Kincaid T.M., Reynolds L., Larsen D.P., 1998, A process for developing and evaluating indices of fish assemblage integrity. Can. J. Fish. Aquat. Sci. 55, 1618-1631.

ISRS, 2004, Sustainable fisheries management in coral reef ecosystems, International Society for Reef Studies, pp. 14-27.

Karr J.R., 1981, Assessment of biotic integrity using fish communities. Fisheries 6, 21-27.

Le Pape O., Holley J., Guérault D., Désaunay Y., 2003, Quality of coastal and estuarine essential fish habitats: estimations based on the size of juvenile common sole (Solea solea L.). Estuar. Coast. Shelf Sci. 58, 793-803.

Léauté J.-P., 2006, Les flottilles de pêche dans la mer territoriale du golfe de Gascogne. In : Chaussade J., Guillaume J. (eds.) Pêche et Aquaculture - Pour une exploitation durable des ressources vivantes de la mer et du littoral. Presses Universitaires de Rennes, pp. 337-352.

Link J.S., 2005, Translating ecosystem indicators into decision criteria. ICES J. Mar. Sci. 62, 569-576.

Lobry J., Mourand L., Rochard E., Elie P., 2003, Structure of the Gironde estuarine fish assemblages: a comparison of European estuaries perspective. Aquat. Living Resour. 16, 47-58. 
McLusky D.S., Elliott M., 2007, The estuarine ecosystem: ecology, threats and management, Third edition. Oxford University Press Inc.

Mercado-Silva N., Lyons J., Salgado-Maldonado G., Medina-Nava M., 2002, Validation of a fish-based index of biotic integrity for the streams and rivers of central Mexico. Rev. Fish Biol. Fish. 12, 179-191.

Methratta E.T., Link J.S., 2006, Evaluation of quantitative indicators for marine fish communities. Ecol. Indic. 6, 575-588.

Mouillot D., Spatharis S., Reizopoulou S., Laugier T., Sabetta L., Basset A., Do Chi T., 2006, Alternatives to taxonomic-based approaches to assess changes in transitional water communities. Aquat. Conserv. Mar. Freshw. Ecosyst. 16, 469-482.

Neuheimer A.B., Taggart C.T., 2007, The growing degree-day and fish size-at-age: the overlooked metric. Can. J. Fish. Aquat. Sci. 64, 375-385.

Rice J., 2003, Environmental health indicators. Ocean Coast. Manage. 46, 235-259.

Rochet M.-J., Whitfiel, A.K., Potte, I.C., Blabe S.J.M., Cyrus D.P., Nordlie F.G., Harrison T.D., 2005, Combining indicator trends to assess ongoing changes in exploited fish communities: diagnostic of communities off the coasts of France. ICES J. Mar. Sci. 62, $1647-1664$.
Rochet M.-J., Trenkel V.M., 2003, Which community indicators can measure the impact of fishing? A review and proposals. Can. J. Fish. Aquat. Sci. 60, 86-99.

Roset N., Grenouillet G., Goffaux D., Pont D., Kestemont P., 2007, A review of existing fish assemblage indicators and methodologies. Fish. Manage. Ecol. 14, 393-405.

Shin Y.J., Rochet M.J., Jennings S., Field J.G., H. Gislason H., 2005, Using size-based indicators to evaluate the ecosystem effects of fishing. ICES J. Mar. Sci. 62, 384-396.

Thiel R., Sepulveda A., Kafemann R., Nellen W., 1995, Environmental factors as forces structuring the fish community of the Elbe Estuary. J. Fish Biol. 46, 47-69.

Wasson J.G., Villeneuve B., Mengin N., Pella H., Chandesris A., 2005, Modèles pressions / impacts. Approche méthodologique, modèles d'extrapolation spatiale et modèles de diagnostic de l'état écologique basés sur les invertébrés en rivière (IBGN, Indice biologique global normalisé). Rapp. Cemagref Lyon BEA/LHQ, Lyon.

Whitfield A.K., Elliott M., 2002, Fishes as indicators of environmental and ecological changes within estuaries: a review of progress and some suggestions for the future. J. Fish Biol. 61, 229-250. 
Erratum

\title{
Assessment of the ecological status of coastal areas and estuaries in France, using multiple fish-based indicators: a comparative analysis on the Vilaine estuary
}

\author{
Anik Brind' Amour ${ }^{1, a}$ and Jérémy Lobry ${ }^{2}$ \\ 1 IFREMER, Centre de Nantes, rue de l'île d'Yeu, BP 21105, 44311 Nantes Cedex 03, France \\ 2 CEMAGREF, Groupement de Bordeaux, 50 avenue de Verdun, 33612 Cestas Gazinet Cedex, France
}

Aquat. Living Resour. 22, 559-572 (2009), DOI: 10.1051/alr/2009052

A reference cited in this article (Brind'Amour and Lobry 2009) needs to be corrected. The right reference is:

Rochet M.-J., Trenkel V., Bellail R., Coppin F., Le Pape O., Mahé J.-C., Morin J., Poulard J.-C., Schlaich I., Souplet A., Vérin Y., Bertrand J., 2005, Combining indicator trends to assess ongoing changes in exploited fish communities: diagnostic of communities off the coasts of France. ICES J. Mar. Sci. 62, 1647-1664.

\footnotetext{
a Corresponding author: Anik.Brindamour@ifremer.fr
} 